\title{
Rencana Kegiatan Teknis dan Ekonomis Reklamasi Lahan Bekas Tambang Andesit di PT X Desa Cipinang, Kecamatan Rumpin, Kabupaten Bogor Provinsi Jawa Barat
}

\author{
Iqbal Ismail* \\ Prodi Teknik Pertambangan, Fakultas Teknik, Universitas Islam Bandung, \\ Indonesia. \\ *iqbalismailun@gmail.com
}

\begin{abstract}
PT X is a private mining company engaged in the mining of Andesite Quarry located in Cipinang Village, Rumpin District, Bogor Regency, West Java Province. With a total area of \pm 105 Ha. One part of the mining industry is reclamation activities, where reclamation itself is a very mandatory thing to do, because exmining land activities can change the landscape and land use of an area. Reclamation is an activity that aims to improve or organize land that has been disturbed due to mining activities so that it can function and be useful according to its necessarily. The purpose of this research is to know the technical plan for land management, revegetation and care and maintenance in an area ex-andesite mining activities where reclamation activities will be carried out. Another objective of this activity is to find out the total cost required for the planned reclamation activity in terms of its economics. The plan for the technical scheme of reclamation to be reclaimed is implemented out from 2022-2026 with the reclamation area in accordance with the area being mined. The total area to be reclaimed is $5.0 \mathrm{Ha}$, at first stage of land management, there is mechanical equipment will be used such as Kobelco SK330 Excavator, FM260 JD - Hino 500 Dumptruck, and Komatsu D85PX-18 Bulldozer. At second stage revegetation (replantation) plants used are main plants in the form of Jabon plants (Neolamarckia cadamba), insert plants in the form of Banana trees (Musa acuminata) and cover crops in the form of Peanut (Mucuna bracteata). This reclamation technical plan will be continued until the last stage there is treatment and maintenance of revegetation plants so that plant growth can be optimal and the success of reclamation is $100 \%$. Based on the result of this researches, it can be concluded that the Mining Business Permit (MBP) for the production operation activities of PT X will expire in 2025 and will enter the last year of reclamation implementation. The total budget and cost for this reclamation plan is Rp 970.162.094,--
\end{abstract}

Keywords: Reclamation Plan, Technical Plan of Reclamation Plan, Economical of Reclamation Plan.

Abstrak. PT X merupakan perusahaan tambang swasta yang bergerak pada bidang pertambangan Quarry Andesit yang berlokasi di Kampung Pabuaran, Desa Cipinang, Kecamatan Rumpin, Kabupaten Bogor, Provinsi Jawa Barat. Dengan luas wilayah keseluruhan $\pm 105 \mathrm{Ha}$. Salah satu bagian dari industri pertambangan adalah kegiatan reklamasi, di mana reklamasi sendiri adalah hal yang bersifat sangat wajib dilakukan, karena lahan bekas kegiatan penambangan dapat merubah bentang alam maupun tataguna lahan suatu wilayah. Reklamasi merupakan kegiatan yang bertujuan untuk memperbaiki atau menata lahan yang sudah terganggu akibat adanya kegiatan penambangan agar dapat berfungsi dan berguna sesuai peruntukannya. Tujuan dari penelitian ini yaitu mengetahui rencana teknis penataan lahan, revegetasi serta perawatan dan pemeliharaan pada suatu area bekas kegiatan penambangan batu andesit yang akan dilakukan kegiatan reklamasi. Tujuan lain dari kegiatan ini, yaitu untuk mengetahui total biaya yang dibutuhkan untuk rencana kegiatan reklamasi ditinjau dari sisi keekonomisannya. Rencana skema teknis penataan lahan yang akan direklamasi dilakukan dari tahun 2022-2026 dengan luas area reklamasi sesuai dengan luas area yang dilakukan penambangan. Luas total yang akan direklamasi 5,0 Ha. Pada tahapan penatagunaan lahan akan digunakan peralatan mekanis berupa Excavator Kobelco SK330, Dump Truck Hino 500 - FM260JD, dan Bulldozer Komatsu D85PX-18. Pada tahapan revegetasi tanaman yang digunakan antara lain, yaitu tanaman pokok berupa tanaman Jabon (Neolamarckia cadamba), tanaman sisipan berupa pohon Pisang (Musa acuminata) dan tanaman penutup berupa tanaman Kacang-kacangan (Mucuna bracteata). Rencana teknis reklamasi ini akan dilanjutkan hingga tahapan perawatan dan pemeliharaan tanaman revegetasi agar pertumbuhan tanaman dapat optimal dan tercapainya keberhasilan reklamasi sebesar 100\%. Berdasarkan hasil penelitian dapat disimpulkan bahwa Izin Usaha Pertambangan (IUP) untuk kegiatan operasi-produksi PT X akan berakhir pada tahun 2025 dan akan memasuki tahun terakhir pelaksanaan reklamasi. Adapun anggaran total biaya rencana reklamasi ini dibutuhkan sebesar Rp 970.162.094,-.

Kata Kunci: Rencana Reklamasi, Rencana Teknis Reklamasi, Rencana Ekonomis Reklamasi. 


\section{A. Pendahuluan}

PT X merupakan salah satu perusahaan tambang batu andesit yang terletak di Desa Cipinang, Kecamatan Rumpin, Kabupaten Bogor, Provinsi Jawa Barat. Kegiatan penambangan perusahaan menggunakan metode penambangan tambang terbuka, quarry side hill method. Kegiatan penambangan akan mengubah rona permukaan bumi sekaligus fungsi lingkungannya, dengan demikian diperlukan kegiatan reklamasi dimulai dari penataan lahan hingga penanaman kembali.

Pada lokasi penelitian yang menjadi permasalahan adalah rencana teknis dan ekonomis reklamasi yang tidak sesuai karena adanya perubahan rencana penambangan. Keadaan di lapangan ada beberapa lokasi yang terbentuk void geometri jalan yang belum sesuai dengan standar yang telah ditetapkan seperti pada lebar jalan, dimana alat angkut tidak dapat berpapasan langsung dan juga kemiringan jalan yang terlalu curam, sehingga dapat menimbulkan alat angkut tidak dapat bekerja secara optimal dan berpengaruh terhadap waktu edar alat tersebut. Semakin besar waktu edar alat angkut maka produksi akan semakin menurun. Kajian reklamasi tambang untuk mengembalikan alih fungsi lingkungan mengacu pada PP No.78 Tahun 2010 dan Kepmen No. 1827/K/30/MEM/2018 mengenai standar reklamasi dan pascatambang.

Berdasarkan latar belakang yang telah diuraikan, maka perumusan masalah dalam penelitian ini adalah : "Bagaimana rencana teknis dan ekonomis reklamasi lahan bekas tambang andesit terhadap kesesuaiannya dengan PP No.78 Tahun 2010 dan Kepmen No. 1827/K/30/MEM/2018?". Selanjutnya, tujuan dalam penelitian ini diuraikan dalam pokokpokok sebagai berikut.

1. Mengetahui rencana teknis penataan lahan reklamasi.

2. Mengetahui rencana teknis revegetasi.

3. Mengetahui rencana teknis perawatan dan pemeliharaan hasil revegetasi.

4. Menghitung total biaya yang dibutuhkan untuk rencana kegiatan reklamasi.

\section{B. Metodologi Penelitian}

Reklamasi adalah kegiatan yang dilakukan sepanjang tahapan Usaha Pertambangan untuk menata, memulihkan, dan memperbaiki kualitas lingkungan dan ekosistem agar dapat berfungsi kembali sesuai peruntukannya. (UU No.3 Tahun 2020). Pemegang IUP Operasi Produksi dan IUPK Operasi Produksi wajib melaksanakan reklamasi dan pascatambang. (PP No.78 Tahun 2010).

1. Persiapan Lahan

Persiapan lahan yang akan dilakukan reklamasi merupakan kegiatan yang dilakukan untuk mempersiapkan area reklamasi meliputi luasan area, kedalaman lokasi yang akan dilakukan reklamasi.

2. Penataan Lahan

Penataan lahan (recontouring/reshaping) dilakukan menggunakan alat bulldozer berupa kegiatan penimbunan area bekas lahan bukaan tambang dengan tanah penutup (overburden).

3. Penebaran Top Soil

Penebaran top soil adalah kegiatan yang dilakukan dengan menebarkan tanah humus, dimana tanah humus tersebut akan dijadikan lokasi untuk revegetasi atau penanaman kembali tumbuhan.

4. Revegetasi

Revegetasi adalah kegiatan penanaman kembali area yang sudah dilakukan penataan lahan, dimana terdiri atas tanaman pokok, tanaman sisipan dan tanaman penutup.

5. Pemeliharaan dan Perawatan

Pemeliharaan dan perawatan adalah kegiatan terakhir dalam kegiatan reklamasi berupa pemberian pupuk pada tanaman hingga pemberian obat-obat (insektisida) tanaman.

\section{Hasil Penelitian dan Pembahasan}

\section{Luasan Area Penambangan dan Reklamasi}

Berikut adalah hasil penelitian yang dilakukan untuk mengetahui rencana luasan bukaan 
tambang dan juga luasan reklamasi. Rencana luasan tersebut dapat dilihat pada tabel 1.

Tabel 1. Rencana Luas Penambangan dan Reklamasi

\begin{tabular}{|c|c|c|c|}
\hline Tahun & Lokasi & $\begin{array}{c}\text { Rencana Luas } \\
\text { Bukaan Tambang (Ha) }\end{array}$ & $\begin{array}{c}\text { Recana Luas } \\
\text { Reklamasi (Ha) }\end{array}$ \\
\hline 2021 & Blok Malimping 1 & 1,93 & - \\
\hline 2022 & Blok Malimping 1 & 0,82 & 1,93 \\
\hline 2023 & Blok Malimping 2 & 1,08 & 0,82 \\
\hline 2024 & Blok Kiara & 0,66 & 1,08 \\
\hline 2025 & Blok Tarisi & 0,51 & 0,66 \\
\hline 2026 & Blok Tarisi & - & 0,51 \\
\hline & Total (Ha) & $\mathbf{5}$ & $\mathbf{5}$ \\
\hline
\end{tabular}

Kebutuhan Material Reklamasi

Kebutuhan material reklamasi terdiri atas overburden dan topsoil, di mana overburden digunakan pada kegiatan penataan lahan, sedangkan top soil digunakan pada tahapan penebaran sebagai sumber hara bagi tanaman revegetasi. Hasil perhitung an kebutuhan material rerklamasi dapat dilihat pada tabel 2 .

Tabel 2. Kebutuhan Material Reklamasi

\begin{tabular}{|c|c|c|c|c|}
\hline \multirow{2}{*}{ Tahun } & \multicolumn{2}{|c|}{ Kebutuhan Material Reklamasi (LCM) } & \multicolumn{2}{c|}{ Kebutuhan Material Pemadatan (CCM) } \\
\cline { 2 - 5 } & Overburden & Top Soil & Overburden & Top Soil \\
\hline 2022 & 12.725 & 10.604 & 11.580 & 9.650 \\
\hline 2023 & 31.538 & 6.758 & 28.700 & 6.150 \\
\hline 2024 & 77.142 & 19.582 & 70.200 & 17.820 \\
\hline 2025 & 38.439 & 16.318 & 34.980 & 14.850 \\
\hline 2026 & 22.978 & 12.890 & 20.910 & 11.730 \\
\hline Total & $\mathbf{1 8 2 . 8 2 4}$ & $\mathbf{6 6 . 1 5 4}$ & $\mathbf{1 6 6 . 3 7 0}$ & $\mathbf{6 0 . 2 0 0}$ \\
\hline
\end{tabular}

Produktivitas Peralatan Mekanis

Peralatan mekanis yang dilakukan dalam kegiatan reklamasi ini, yaitu Excavator Kobelco SK330 dengan produktivitas 152,78 LCM/Jam/Alat, kemudian Dumptruck Hino 500 FM260JD dengan produktivitas 37,03 LCM/Jam/Alat, serta Bulldozer Komatsu D85PX-18 dengan nilai produktivitas sebesar143,18 LCM/Jam/Alat. Hasil perhitungan produktivitas peralatan mekanis dapat dilihat pada tabel 3, tabel 4 dan tabel 5 .

Tabel 3. Produktivitas Excavator Kobelco SK330

\begin{tabular}{|c|l|c|c|}
\hline \multicolumn{2}{|l}{ Parameter } & Nilai & Satuan \\
\hline \multirow{4}{*}{$\begin{array}{c}\text { Excavator } \\
\text { Kobelco SK330 }\end{array}$} & Kapasitas Bucket $\left(\mathrm{H}_{\mathrm{m}}\right)$ & 1,6 & LCM \\
\cline { 2 - 4 } & Fill Factor $\left(\mathrm{FF}_{\mathrm{m}}\right)$ & 90 & $\%$ \\
\cline { 2 - 4 } & Swell Factor $(\mathrm{SF})$ & 80 & $\%$ \\
\cline { 2 - 4 } & Efisiensi Kerja $\left(\mathrm{E}_{\mathrm{m}}\right)$ & 83,33 & detik \\
\cline { 2 - 4 } & Cycle Time $(\mathrm{CT})$ & 22,62 & menit \\
\cline { 2 - 4 } & Produktivitas $(\mathbf{P m} \mathbf{1})$ & 0,38 & $\mathbf{1 5 2 , 7 8}$ \\
\hline
\end{tabular}

Tabel 4. Produktivitas Dumptruck Hino 500 FM260JD

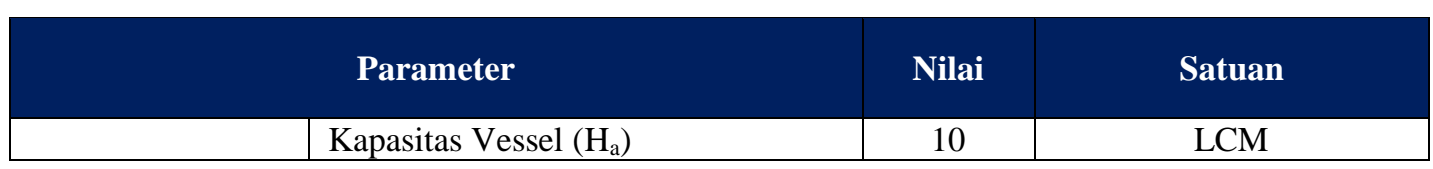




\begin{tabular}{|l|l|c|c|} 
& Kapasitas Bucket $\left(\mathrm{H}_{\mathrm{m}}\right)$ & 1,6 & LCM \\
\cline { 2 - 4 } & Fill Factor $\left(\mathrm{FF}_{\mathrm{m}}\right)$ & 90 & $\%$ \\
\cline { 2 - 4 } & Swell Factor $(\mathrm{SF})$ & 80 & $\%$ \\
\cline { 2 - 4 } Dumptruck Hino & Efisiensi Kerja $\left(\mathrm{E}_{\mathrm{a}}\right)$ & 83,33 & \% \\
\cline { 2 - 4 } 500 FM260JD & Jumlah Pemuatan $\left(\mathbf{n}_{\mathrm{p}}\right)$ & 1,95 & menit \\
\cline { 2 - 4 } & Kembali Kosong $\left(\mathrm{T}_{\mathrm{k}}\right)$ & 0,75 & menit \\
\cline { 2 - 4 } & Manuver Kosong $\left(\mathrm{T}_{\mathrm{mk}}\right)$ & 2,15 & menit \\
\cline { 2 - 4 } & Pemuatan $\left(\mathrm{T}_{\mathrm{l}}\right)$ & 2,65 & menit \\
\cline { 2 - 4 } & Berangkat Isi $\left(\mathrm{T}_{\mathrm{i}}\right)$ & 0,60 & menit \\
\cline { 2 - 4 } & Manuver Isi $\left(\mathrm{T}_{\mathrm{mi}}\right)$ & 0,65 & menit \\
\cline { 2 - 4 } & Pengosongan $\left(\mathrm{T}_{\mathrm{d}}\right)$ & $\mathbf{8 , 7 5}$ & menit \\
\cline { 2 - 4 } & Cycle Time $(\mathbf{C T})$ & $\mathbf{3 7 , 0 3}$ & LCM/Jam/Alat \\
& Produktivitas $\left(\mathbf{P}_{\mathbf{a}} \mathbf{1}\right)$ & &
\end{tabular}

Tabel 5. Produktivitas Bulldozer Komatsu D85PX-18

\begin{tabular}{|c|c|c|c|}
\hline & Parameter & Nilai & Satuan \\
\hline \multirow{10}{*}{$\begin{array}{c}\text { Bulldozer } \\
\text { Komatsu } \\
\text { D85PX-18 }\end{array}$} & Blade Capacity $(\mathrm{H})$ & 5,2 & LCM \\
\hline & Forward Speed (F) & 50 & $\mathrm{~m} / \mathrm{menit}$ \\
\hline & Reverse Speed (R) & 83,33 & $\mathrm{~m} / \mathrm{menit}$ \\
\hline & Waktu Ganti Gigi (Z) & 0,1 & menit \\
\hline & Grade Factor (e) & 95 & $\%$ \\
\hline & Efisiensi Kerja $\left(E_{a}\right)$ & 83,33 & $\%$ \\
\hline & Swell Factor (SF) & 80 & $\%$ \\
\hline & Jarak Pergerakan Bulldozer (D) & 40 & $\mathrm{~m}$ \\
\hline & Cycle Time $(\mathrm{CT})$ & 1,38 & menit \\
\hline & Produktivitas (Pa1) & 143,18 & LCM/Jam/Alat \\
\hline
\end{tabular}

\section{Penataan Lahan}

Penatanaan lahan merupakan kegiatan yang dilakukan untuk meratakan kembali area bekas kegiatan penggalian maupun penambangan. Alat yang digunakan pada penataan lahan yaitu bulldozer di mana pemakaian bahan bakarnya sebesar 28 liter/jam, di mana rencana pengerjaan penataan lahan akan dilakukan selama 163 hari. Rencana dari penataan lahan dapat dilihat pada tabel 6.

Tabel 6. Penataan Lahan

\begin{tabular}{|c|c|c|c|c|c|c|}
\hline \multirow{2}{*}{$\begin{array}{c}\text { Alat } \\
\text { Mekanis }\end{array}$} & \multirow[t]{2}{*}{ Parameter } & $\begin{array}{l}\text { Tahun } \\
\text { I }\end{array}$ & $\begin{array}{c}\text { Tahun } \\
\text { II }\end{array}$ & $\begin{array}{c}\text { Tahun } \\
\text { III }\end{array}$ & $\begin{array}{l}\text { Tahun } \\
\text { IV }\end{array}$ & $\begin{array}{c}\text { Tahun } \\
\text { V }\end{array}$ \\
\hline & & 2022 & 2023 & 2024 & 2025 & 2026 \\
\hline \multirow{6}{*}{$\begin{array}{c}\text { Bulldozer } \\
\text { Komatsu } \\
\text { D85PX-18 }\end{array}$} & Luas (Ha) & 1,93 & 0,82 & 1,08 & 0,66 & 0,51 \\
\hline & Volume (LCM) & 12.725 & 31.538 & 77.142 & 38.439 & 22.978 \\
\hline & Waktu Operasi Alat (Jam) & 88,88 & 220,27 & 538,78 & 268,47 & 160,48 \\
\hline & Kebutuhan Bahan Bakar (L) & $2.488,52$ & $6.167,57$ & $15.085,83$ & $7.517,13$ & $4.493,52$ \\
\hline & $\begin{array}{c}\text { Total Waktu Pengerjaan } \\
\text { (Hari/Tahun) }\end{array}$ & 12 & 28 & 68 & 34 & 21 \\
\hline & Total Pengerjaan (Hari) & \multicolumn{5}{|c|}{163} \\
\hline
\end{tabular}

\section{Penebaran Top Soil}

Penebaran top soil merupakan kegiatan yang dilakukan untuk menebarkan tanah pada area yang sudah dilakukan penataan lahan, dimana tanah yang digunakan tanah humus sebagai sumber 
hara untuk tanaman revegetasi. Alat yang digunakan pada penataan lahan yaitu excavator, dumptruck, dan bulldozer di mana pemakaian bahan bakar untuk excavator sebesar 25 liter/jam, dumptruck 25 liter/jam, dan bulldozer sebesar 28 liter/jam, di mana rencana pengerjaan penebaran top soil akan dilakukan selama 174 hari. Rencana dari penebaran topsoil dapat dilihat pada tabel 7.

Tabel 7. Penebaran Topsoil

\begin{tabular}{|c|c|c|c|c|c|c|}
\hline \multirow[t]{2}{*}{ Parameter } & \multirow[t]{2}{*}{ Parameter } & $\begin{array}{c}\text { Tahun } \\
\text { I }\end{array}$ & $\begin{array}{c}\text { Tahun } \\
\text { II }\end{array}$ & $\begin{array}{l}\text { Tahun } \\
\text { III }\end{array}$ & $\begin{array}{c}\text { Tahun } \\
\text { IV }\end{array}$ & $\begin{array}{c}\text { Tahun } \\
\text { V }\end{array}$ \\
\hline & & 2022 & 2023 & 2024 & 2025 & 2026 \\
\hline & Luas (Ha) & 1,93 & 0,82 & 1,08 & 0,66 & 0,51 \\
\hline & Volume (LCM) & 10.604 & 6.758 & 19.582 & 16.318 & 12.890 \\
\hline \multirow{4}{*}{$\begin{array}{c}\text { Excavator } \\
\text { Kobelco } \\
\text { SK330 }\end{array}$} & Waktu Operasi Alat (Jam) & 69,41 & 44,24 & 128,17 & 106,81 & 84,37 \\
\hline & Kebutuhan Bahan Bakar (L) & $1.735,25$ & $1.105,89$ & $3.204,37$ & $2.670,31$ & $2.109,27$ \\
\hline & $\begin{array}{c}\text { Total Waktu Pengerjaan } \\
\text { (Hari/Tahun) }\end{array}$ & 9 & 6 & 17 & 14 & 11 \\
\hline & Total Pengerjaan (Hari) & \multicolumn{5}{|c|}{57} \\
\hline \multirow{4}{*}{$\begin{array}{c}\text { Dumptruck } \\
\text { Hino 500 } \\
\text { FM260JD }\end{array}$} & Waktu Operasi Alat (Jam) & 71,60 & 45,63 & 132,22 & 110,18 & 87,03 \\
\hline & Kebutuhan Bahan Bakar (L) & $3.436,75$ & $2.190,26$ & $6.346,41$ & $5.288,67$ & $4.177,52$ \\
\hline & $\begin{array}{c}\text { Total Waktu Pengerjaan } \\
\text { (Hari/Tahun) }\end{array}$ & 9 & 6 & 17 & 14 & 11 \\
\hline & Total Pengerjaan (Hari) & \multicolumn{5}{|c|}{57} \\
\hline \multirow{4}{*}{$\begin{array}{c}\text { Bulldozer } \\
\text { Komatsu } \\
\text { D85PX-18 }\end{array}$} & Waktu Operasi Alat (Jam) & 74,06 & 47,20 & 136,77 & 113,97 & 90,03 \\
\hline & Kebutuhan Bahan Bakar (L) & $2.073,76$ & $1.321,62$ & $3.829,48$ & $3.191,23$ & $2.520,75$ \\
\hline & $\begin{array}{c}\text { Total Waktu Pengerjaan } \\
\text { (Hari/Tahun) }\end{array}$ & 10 & 6 & 18 & 15 & 12 \\
\hline & Total Pengerjaan (Hari) & \multicolumn{5}{|c|}{60} \\
\hline \multicolumn{2}{|c|}{ Total Pengerjaan (Hari) } & \multicolumn{5}{|c|}{174} \\
\hline
\end{tabular}

\section{Revegetasi}

Revegetasi merupakan kegiatan penanaman kembali pada suatu lahan yang sudah dilakukan penataan lahan dan penebaran top soil. Revegetasi terdiri atas pengadaan bibit tanaman pokok berupa Pohon Jabon (Neolamarckia cadamba), tanaman sisipan berupa Pohon Pisang (Musa acuminata), dan tanapan penutup berupa Kacang-kacangan (Mucuna bracteata), setelah dilakukan pengadaan bibit maka dilanjutkan dengan kegiatan penanaman dan pemberian pupuk hingga perawatan dan pemeliharaan. Rencana pengerjaan revegetasi dapat dilihat pada tabel 8 .

\section{Tabel 8. Revegetasi}

\begin{tabular}{|c|c|c|c|c|c|}
\hline \multirow{2}{*}{ Jenis Kegiatan Revegetasi } & \multicolumn{5}{|c|}{ Waktu Pengerjaan (Hari) } \\
\cline { 2 - 7 } & $\begin{array}{c}\text { Tahun } \\
\mathbf{2 0 2 2}\end{array}$ & $\begin{array}{c}\text { Tahun } \\
\mathbf{2 0 2 3}\end{array}$ & $\begin{array}{c}\text { Tahun } \\
\mathbf{2 0 2 4}\end{array}$ & $\begin{array}{c}\text { Tahun } \\
\mathbf{2 0 2 5}\end{array}$ & $\begin{array}{c}\text { Tahun } \\
\mathbf{2 0 2 6}\end{array}$ \\
\hline $\begin{array}{c}\text { Tanaman Pokok } \\
\text { (Pioneer) }\end{array}$ & 31 & 14 & 18 & 11 & 9 \\
\hline $\begin{array}{c}\text { Tanaman Sisipan } \\
\text { Tanaman Penutup } \\
\text { (Cover Crop) }\end{array}$ & 8 & 4 & 5 & 3 & 3 \\
\hline Pemeliharaan dan Perawatan & 6 & 1 & 1 & 1 & 1 \\
\hline
\end{tabular}




\begin{tabular}{|c|c|c|c|c|c|}
\hline Total Hari Pertahun & 46 & 22 & 28 & 17 & 15 \\
\hline Total Hari Selama 5 Tahun & \multicolumn{3}{|c|}{128} & \\
\hline
\end{tabular}

\section{Total Biaya Reklamasi}

Total biaya reklamasi merupakan jumlah keseluruhan biaya yang dibutuhkan pada tahapan penataan lahan, penebaran top soil, dan revegetasi. Total biaya yang dibutuhkan adalah sebesar Rp 970.162.094,-. Total biaya reklamasi dapat dilihat pada tabel 9.

Tabel 9. Total Biaya Reklamasi

\begin{tabular}{|c|c|c|c|c|c|c|}
\hline \multirow{2}{*}{$\begin{array}{c}\text { Rekapitulasi Total } \\
\text { Estimasi Biaya } \\
\text { Reklamasi }\end{array}$} & \multirow[b]{2}{*}{ Satuan } & Tahun I & Tahun II & Tahun III & Tahun IV & Tahun V \\
\hline & & 2022 & 2023 & 2024 & 2025 & 2026 \\
\hline \multicolumn{7}{|l|}{ Biaya Langsung } \\
\hline \multicolumn{7}{|c|}{ (A) Biaya Penatagunaan Lahan : } \\
\hline $\begin{array}{l}\text { a. Penataan Permukaan } \\
\text { Lahan }\end{array}$ & \multirow{2}{*}{$\begin{array}{l}\text { Rupiah } \\
\text { (Rp) }\end{array}$} & 26.494 .940 & 665.526 .505 & 161.881 .453 & 83.262 .147 & 50.441 .620 \\
\hline $\begin{array}{l}\text { b. Penebaran Tanah } \\
\text { Pucuk }\end{array}$ & & 76.497 .740 & 48.763 .753 & 141.238.643 & 117.704 .451 & 92.981 .646 \\
\hline Sub Total (A) & $\begin{array}{c}\text { Rupiah } \\
\text { (Rp) }\end{array}$ & 102.992 .680 & 115.290 .680 & 306.120 .097 & 200.966.598 & 143.423 .266 \\
\hline \multicolumn{7}{|l|}{ (B) Biaya Revegetasi : } \\
\hline a. Pengadaan Bibit & \multirow{4}{*}{$\begin{array}{l}\text { Rupiah } \\
\text { (Rp) }\end{array}$} & 30.565 .750 & 13.240 .888 & 17.647 .718 & 10.986 .543 & 8.639 .009 \\
\hline b. Penanaman & & 5.112 .257 & 2.172 .047 & 2.860 .745 & 1.748 .233 & 1.350 .907 \\
\hline c. Pemupukan & & 926.250 & 404.666 & 537.444 & 336.956 & 266.357 \\
\hline $\begin{array}{l}\text { d. Pemeliharaan dan } \\
\text { Perawatan }\end{array}$ & & 1.756 .602 & 748.948 & 989.919 & 607.119 & 470.838 \\
\hline Sub Total (B) & $\begin{array}{c}\text { Rupiah } \\
\text { (Rp) }\end{array}$ & 38.360 .859 & 16.566 .549 & 22.035 .827 & 13.678 .851 & 10.727.111 \\
\hline Sub Total $(A)+(B)$ & $\begin{array}{c}\text { Rupiah } \\
\text { (Rp) }\end{array}$ & 141.353.539 & 131.856 .806 & 328.155 .923 & 214.645.449 & 154.150 .377 \\
\hline $\begin{array}{c}\text { Total Keseluruhan } \\
\text { Biaya Rencana } \\
\text { Reklamasi }\end{array}$ & $\begin{array}{c}\text { Rupiah } \\
\text { (Rp) }\end{array}$ & & & & & 970.162 .094 \\
\hline
\end{tabular}

\section{Kesimpulan}

Berdasarkan hasil penelitian, dapat ditarik kesimpulan, yaitu :

1. Rencana teknis penatagunaan lahan reklamasi dilakukan pada tahun 2022-2026 dengan luas total 5,0 Ha.

2. Rencana teknis revegetasi dilakukan pada tahun 2022-2026 tanaman yang digunakan pada kegiatan revegetasi, yaitu Pohon Jabon (Neolamarckia cadamba), Pohon Pisang (Musa acuminata), dan Tanaman Kacang-kacangan (Mucuna braacteata).

3. Rencana teknis pemeliharaan dan perawatan dilakukan pada tahun 2022-2026, meliputi pemupukan, penyulaman, penyiraman, serta pemberian insektisida tanaman.

4. Total biaya reklamasi pada tahun 2022-2026 sebesar Rp 970.162.094,-- 


\section{Daftar Pustaka}

[1] Anonim, 2020, "Undang-Undang Nomor 3 Tahun 2020 Tentang Perubahan Undang- Undang Nomor 4 Tahun 2009 (Pertambangan Mineral dan Batubara)" Pemerintah Republik Indonesia, Jakarta, Indonesia.

[2] Anonim, 2010, "Peraturan Pemerintah Nomor 78 Tahun 2010 tentang Reklamasi dan Pascatambang", Pemerintah Republik Indonesia, Jakarta, Indonesia.

[3] Anonim, 2018, "Peraturan Menteri Lingkungan Hidup dan Kehutanan Nomor P.27/Menlhk/Setjen/Kum.1/7/2018 Tentang Pedoman Pinjam Pakai Kawasan Hutan". Kementerian Lingkungan Hidup dan Kehutan Republik Indonesia, Jakarta, Indonesia.

[4] Anonim, 2018, "Keputusan Menteri Energi dan Sumber Daya Mineral Republik Indonesia Nomor 1827 K/30/MEM/2018 Tentang Pedoman Pelaksanaan Kaidah Teknik Pertambangan yang Baik”. Kementerian Energi dan Sumber Daya Mineral Republik Indonesia, Jakarta, Indonesia.

[5] Anonim, 2008, "Peraturan Daerah Kabupaten Bogor Nomor 19 Tahun 2008 Tentang Rencana Tata Ruang Wilayah (RTRW) Kabupaten Bogor Tahun 2005-2025". Pemerintahan Daerah Kabupaten Bogor, Indonesia.

[6] Anonim, 2020, “Kobelco SK330 Specification", Kobelco Construction Machinery, Tokyo, Japan.

[7] Anonim, 2020, "Hino 500 FM260JD Spefication", Hino Motor Industries, Tokyo, Japan.

[8] Anonim, 2020, “Komatsu D85PX-18 Specification”, Komatsu Industries, Tokyo, Japan.

[9] Priyono, dkk, 2002, "Panduan Kehutanan Indonesia", Badan Penelitian dan Pengembangan Kehutanan dan Perkebunan, Kementerian Kehutanan dan Lingkungan Hidup, Jakarta, Indonesia.

[10] Prodjosumarto, Partanto. 1993, "Pemindahan Tanah Mekanis", Jurusan Teknik Pertambangan Fakultas Teknologi Mineral, Institut Teknologi Bandung, Bandung.

[11] Turkandi, dkk, 1992, "Peta Geologi Lembar Jakarta dan Kepulauan Seribu, Jawa", Pusat Penelitian dan Pengembangan Geologi, Bandung, Indonesia. 